\title{
Bestimmung des Permanganat-Verbrauches eines viele Chloride enthaltenden Wassers.
}

\author{
Von
}

\author{
Dr. Ruppin in Kiel.
}

Bestimmt man das Reduktionsvermögen eines Wassers gegen Kaliumpermanganat in alkaliseher Lösung nach den "Vereinbarungen", so hat selbst ein Kochsalzgehalt, der $8000 \mathrm{mg}$ Chlor im Liter entspricht, keinen Ein-

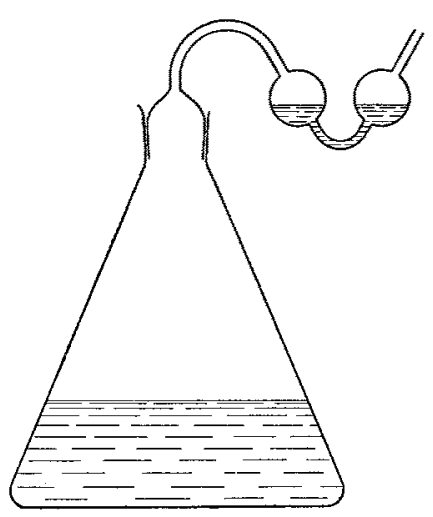

Fig. 5. fluß auf die verbrauchte Permanganatmenge ${ }^{1}$ ).

Anders gestaltet sich die Reaktion, wenn im Wasser ein Gemisch von Chloriden enthalten ist. Schon. im Ostsee-Wasser von $1 \%$ Salzgehalt wird bei der Temperatur von $60-50^{\circ}$ das Permanganat von Chlor nach dem Ansäuren angegriffen, auch ist es nicht möglich einen scharfen Endpunkt beim Zurücktitrieren der Oxalsäure zu finden. Unter diese Temperatur herunterzugehen verbietet sich dadurch, daß dann der Umsatz von Oxalsäure mit Permanganat zu träge verläuft.

Für solche Fälle habe ich folgende Änderung des Verfahrens vorgenommen:

Die Oxydation geschieht in der vorgeschriebenen Weise in einem Erlenmeyer-Kolben, in dessen Hals ein eingeschliffener Aufsatz (vergl. Fig. 5) eingesetzt werden kann. Der Aufsatz wird mit etwa 10\%-iger Kaliumjodidlösung beschickt. Nach beendeter Oxydation kühlt man auf $60^{\circ} \mathrm{ab}$, säuert an und setzt den Aufsatz sofort auf. Zur Sicherheit kann man den Schliff noch mit einigen Tropfen Kaliumjodidlösung dichten. Wenn die rote Farbe des Permanganates verschwunden ist, läßt man durch den Aufsatz 5 ccm der Kaliumjodidlösung eintreten, kühlt auf Zimmertemperatur weiter, spült den Inhalt des Aufsatzes in den Kolben und titriert mit 1/100 N.-Thiosulfatlösung oder setzt $10 \mathrm{cem}$ Thiosulfatlösung zu und titriert mit 1/100 N.-Jodlösung zurück. Permanganatlösung und Thiosulfatlösung sind auf die Jodlösung eingestellt ${ }^{2}$ ).

Das Verfahren liefert stets sehr schön übereinstimmende Ergebnisse.

1) Diese Zeitschrift $1900,3,677$.

2) Jodkalium zum Zuricktitrieren des aberschüssigen Permanganats hat schon Tidy benutzt. Vergl. Tiemann-Gurtner's Handbuch der Untersuchung und Benrteilung der Wässer. 1895. S. 289. 